\title{
Compliances of Road Safety Practices and Associated Factors for Penalization against Traffic Offences among Commercial Motorcyclists: A Case of Dodoma City, Tanzania
}

\section{Evaristus Peter Makota ${ }^{1 *}$ and Stephen Mathew Kibusi ${ }^{2}$}

${ }^{1}$ Training and Continuous Professional Development, Njombe RRH, Tanzania

${ }^{2}$ College of Health Sciences, University of Dodoma, Tanzania

*Corresponding Author: Evaristus Peter Makota, Training and Continuous

Professional Development, Njombe RRH, Tanzania.
Received: June 08, 2021

Published: July 22, 2021

(C) All rights are reserved by Evaristus Peter

Makota.

\section{Abstract}

Accidents have been observed to hinder individual development and reduce national economic intensification against expectations of Sustainable Development Goals (SDGs). The presence of users of motorcycles and the associated accidents incursion offer a unique challenge in view of inadequate work force, which is frequently lost. However, despite the effort taken by the Government in addressing road safety practices, compliance is still low and reasons for penalization against traffic offences among commercial motorcyclists is continued to worsen the situation, the current study aimed at assessing compliances and reasons for penalization so as to counteract the burden of road traffic injuries. Study involved two hundred fifty two participants randomly selected from registered parking points and the result showed that majority of the commercial motorcyclists had low compliances and most of them were penalized against traffic offences with a couple of reasons including riding without wearing helmet, drunken riding. The result also revealed that, riding experience, possession of license and awareness on speed limits shown closely association with penalization.

Keywords: Compliances; Road Safety Practices; Penalization; Traffic Offences; Commercial Motorcyclists

\section{Abbreviation}

RHH: Regional Referral Hospital

\section{Introduction}

Accidents have been observed to hinder individual development and reduce national economic intensification against expectations of Sustainable Development Goals (SDGs). The presence of users of motorcycles and the associated accidents incursion offer a unique challenge in view of inadequate work force, which is frequently lost. The study determined effectiveness of participatory training in improving knowledge and skills for basic life support among commercial motorcyclists to address the problem.

However, the problem of the road traffic injuries fatalities affecting many countries including Tanzania. It is highly affected de- veloping countries in East Africa and Africa in general with road traffic accidents and injuries [1]. In 2010, the country had the road traffic death rates of 22.7 per 100,000 [2]. The road accidents are rising day after day; for case in point, in 1977-2008 there was about 379, 699 accidents with 48, 754 fatalities and 347, 657 people injured while leaving substantial damages to property. In 2009 to 2011 , the accidents continued to increase to $22,739,24,665$ and 22,508 events per annum respectively.

Traffic disorganization, failure in vehicle inspection, poor maintenance conditions, reckless and drunken driving as well as impunity of infringers, significantly contribute to the occurrence of traffic accidents, especially involving motorcyclists. In addition, the use of cellular phones while riding, driving without valid license, passing traffic red light and U-turn also were reported to contribute on occurrence of road traffic accidents $[3,4]$. 
Despite, the strategies carried by the government of Tanzania including endorsement of Motorcycles Licensing Regulations in 2009 , conducting of education sessions on road safety and raising public awareness through radio and television stations and distribution of fliers yet [5]. The implementation of first and second phases of national road safety operations and road safety week campaigns [6], the problem persists and increasing road traffic injuries and fatalities to 43-56 aged adjusted death rate per 100,000 (World Life Expectancy [7]) whereby economically active age group 18-45 years are more affected and most of them died due to delayed pre-hospital care [8]. The problem had several impacts to the community includes; loss of economically active age group for production, mental and physical disabilities and permanent dependence [9].

This studies therefore, aiming at assessing the compliances of road safety practices and associated factors for penalization against traffic offenses. Moreover, the information gathered to be beneficial to determine the level of compliances of road safety practices and reasons for penalization aim of reducing road traffic injuries fatalities in Tanzania.

The curiosity of this study under its objectives; assessing effect of participatory training in improving knowledge and skills on basic life support and finding satisfaction on training among commercial motorcyclists, seeks to fill the gap of knowledge and skills based on helping casualties with road traffic injuries using established basic life support training manual, which was assessed for its effectiveness and relevance among commercial motorcyclists in Dodoma Municipal, Tanzania.

\section{Aim of the Study}

The study aimed at assessing the compliances of road safety practices and associated factors for penalization against traffic offences among commercial motorcyclists in Dodoma City.

\section{Materials and Methods}

\section{Study design}

A cross sectional study with a quantitative approach was used to evaluate the effectiveness of the training manual for the ultimate purpose of reducing road traffic fatalities $[10,11]$.

\section{Study setting}

This study carried out in Dodoma City, the fast growing city with highly road traffic roadway in Tanzania, whereby commercial mo- torcyclist industry contributing significant means of transportation which accompanied by increasing number of accidents [12,13].

\section{Participants}

Registered commercial motorcyclists offering their services in Dodoma municipal were involved. Total of 886 commercial motorcyclists were already registered by data collection. Those registered with no willing to participate voluntarily, were not included in the study.

\section{Sample size determination and procedure}

Sample size of 268 obtained using formula by Krejcie and Morgan (NP ((1-P)/ (N-1) + P (1-P) [14]. The participants from their 44 registered parking were obtained randomly using lottery approach, whereby the required participants from registered parking points were determined by proportionality.

Required Participants $=$

Total number of study participants in each parking point $\mathrm{x}$ Sample Size

Total number of participants in all parking points

Forty four boxes were prepared equal to the total number of parking points and each box represented one parking point whereby the pieces of papers were kept in, corresponding to the number of registered commercial motorcyclists in those parking points. These pieces of papers numbered according to the required sample size from that parking point as determined by proportionality. Then, participants told to pick up one piece of paper after the box shaken vigorously, to ensure randomization. Then, required sample of study and the numbers recorded. The participants belonging to these numbers constituted the sample size from that parking point.

\section{Instruments}

Data were collected using self-administered questionnaire adopted and modified from Adopted from Motorcyclist's behavior and attitude toward road safety questionnaire by Nordqvist and Petter, (2010). Only questions 14, 16, 23, 28, 33 and 40, which fit with study, were obtained, and modified by adding penalization against traffic violation by Sasidharan (2013). The questionnaire structured with three (3) sections namely: section A with six (6) demographical questions, section $B$ with eight (8) questions pertaining to accident and motorcycling history, section $\mathrm{C}$ comprised with seven (7) questions of compliances of road safety practices 
Compliances of Road Safety Practices and Associated Factors for Penalization against Traffic Offences among Commercial Motorcyclists: A Case of Dodoma City, Tanzania

and section $\mathrm{C}$ was for associated factors for penalization with two (2) questions. Questionnaire was pre tested for assessing its validity and accuracy prior for administration in the actual study.

Data collection and analysis

Data were processed and analyzed using SPSS Statistical for Windows, Version 25.0. A number of significance tests used to confirm whether the observed association between variables was true or by chance as shown in table 3 . A p-value of 0.05 considered significant. Some of the variables were transformed (dichotomized and computed) for further analysis and interpretation.

\section{Result}

Response rate

The study targeted 268 commercial motorcyclists from Dodoma Municipal. From the study, participants attended five training units (Median 8, and Mode 12), 220 (82\%) of the participants attended four units, 43 (16\%) attending all five units and only 5 (2\%) of the participants did not attend any unit. This makes 252 out of 268 sampled commercial motorcyclists participated and filled the questionnaires making a response rate of $94 \%$. According to $\mathrm{Mu}-$ genda, (1999) a response rate of $50 \%$ is adequate for analysis, reporting a rate of $60 \%$ is good, and a response rate of $70 \%$ and over is excellent. Therefore, the response rate in this study was excellent for analysis and reporting. Non-response rate of $6.0 \%$; this means 16 participants were not involved due to fact that some were not participated in intervention and post intervention phases of data collection and therefore excluded from the study.

\begin{tabular}{|l|c|c|c|}
\hline $\begin{array}{l}\text { Total Commercial } \\
\text { Motorcyclists } \\
\text { population }\end{array}$ & $\begin{array}{c}\text { Sample } \\
\text { Size }\end{array}$ & $\begin{array}{c}\text { Response } \\
\text { Rate of } \\
\text { Sample }\end{array}$ & $\begin{array}{c}\text { Non Response } \\
\text { Rate of } \\
\text { Sample }\end{array}$ \\
\hline 886 & 268 & 252 & 16 \\
\hline $100 \%$ & $30.24 \%$ & $94.0 \%$ & $6.0 \%$ \\
\hline
\end{tabular}

Table 1: Response rate of the study.

Source: Filed data, (2019).

\section{Socio-demographic characteristics}

The findings of the study show that all respondents were male, $252(100 \%)$. The demographic variables age of the commercial motorcyclists, were found that a large sample falls between the ages of the 20-29 years which depicts 119 (47.2\%), whereby the sample mean of age was 31.3 , mode of 40 and median age was 30 .
Majority of the respondents had primary level education, which accounts for 154 (61.1\%) as shown in table 2 below.

\begin{tabular}{|l|c|c|c|}
\hline Variables & Variable Categories & $\mathbf{n}$ & $\mathbf{\%}$ \\
\hline Sex & Male & 252 & 100 \\
\hline & Female & 0 & 0 \\
\hline Age (Years) & $20-29$ years & 119 & 47.2 \\
\hline & $30-39$ years & 95 & 37.7 \\
\hline & $40-49$ years & 36 & 14.3 \\
\hline Marital Status & Married & 69 & 27.4 \\
\hline & Not Married & 177 & 70.2 \\
\hline & Divorced & 2 & 0.8 \\
\hline & Widow/Widower & 4 & 1.6 \\
\hline & Married & 69 & 27.4 \\
\hline Educational Level & Primary Level & 154 & 61.1 \\
\hline & Secondary Level & 93 & 36.9 \\
\hline & University Level & 2 & 0.8 \\
\hline & Not Educated & 3 & 1.2 \\
\hline Other Occupation & Yes & 27 & 10.7 \\
\hline & No & 225 & 89.3 \\
\hline Residence & Urbaral & 113 & 44.8 \\
\hline & & 139 & 55.2 \\
\hline
\end{tabular}

Table 2: Socio-demographic characteristics of the commercial motorcyclists in Dodoma city.

Source: Field data (2019).

\section{Accident and motorcycling history}

Majority of the commercial motorcyclists 233 (92.5\%) did not attend BLS training prior an intervention while most of them 171 $(67.9 \%)$ already attended victim with road traffic injuries in duration of twelve months as shown in table 3.

Compliance of road safety practices among commercial motorcyclists in Dodoma City

The current study was interested to determine the compliances of the road safety practices in the aspects of active riding license, overspeed, drunken riding, use of personal protective equipments and penalization. The findings of the study revealed that, out of 252 respondents, $101(40.1 \%)$ possess active riding license while the rest are not which accounts for 151 (59.9\%). Information about 
Compliances of Road Safety Practices and Associated Factors for Penalization against Traffic Offences among Commercial Motorcyclists: A Case of Dodoma City, Tanzania

the use of personal protective equipment when riding was also exhausted including; full-face helmet, open face helmets, safety trouser are listed in the figure 1.

\begin{tabular}{|l|c|c|c|}
\hline Variables & Variable Categories & $\mathbf{n}$ & $\mathbf{\%}$ \\
\hline Attending riding Training & Yes & 66 & 26.2 \\
\hline & No & 186 & 73.8 \\
\hline Ownership of Motorcycle & Self-Ownership & 75 & 29.8 \\
\hline & Employed & 139 & 55.2 \\
\hline Riding Experience & Day Worker & 38 & 15.1 \\
\hline & $1-3$ years & 215 & 85.3 \\
\hline & $4-6$ years & 30 & 11.9 \\
\hline & 6 years and above & 7 & 2.8 \\
\hline Attending RTA victim & $1-3$ years & 215 & 85.3 \\
\hline & Yes & 171 & 67.9 \\
\hline Attending BLS Training & No & 81 & 32.1 \\
\hline & Yes & 19 & 7.5 \\
\hline $\begin{array}{l}\text { Road Traffic Accident } \\
\text { Exposure }\end{array}$ & No & 233 & 92.5 \\
\hline & Yes & 80 & 31.7 \\
\hline
\end{tabular}

Table 3: Accident and motorcycling history of the commercial motorcyclists in Dodoma city.

Source: Field data, (2019).

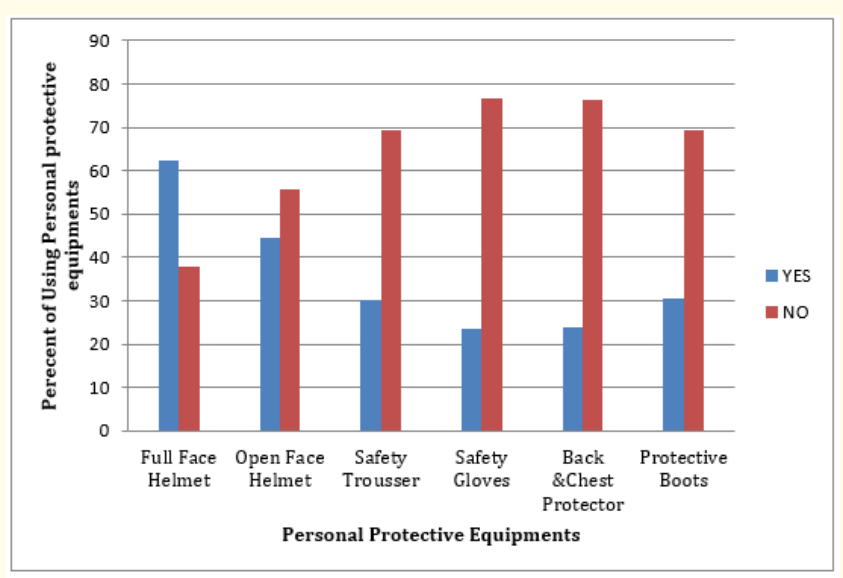

Figure 1: Use of personal protective equipments when riding motorcycles.

The figure above revealed that, the majority of the respondents worn full face helmet 157 (62.3\%) but most of them did not worn safety gloves, 193 (76.6\%), back and chest protector 192 (76.2\%) and protective boots which accounts for 175 (69.4\%). On the other side of riding speed whereby respondents asked question to explore their awareness on riding speed limit, 84 (33.3\%) were aware on this area while 168 (66.7\%) were not aware.

The approach towards riding a motorcycle after drinking alcohol examined through series of claims includes: active drunken riding, hangover drunken and witness on drunken riding also explored as shown on the figure 2 below.

The chart reveals that the problem of drunken riding exist only $75(29.7 \%)$ agreed riding motorcycles while drunk. Often, $72(28.6 \%)$ agreed riding motorcycles while drunk sometime 105

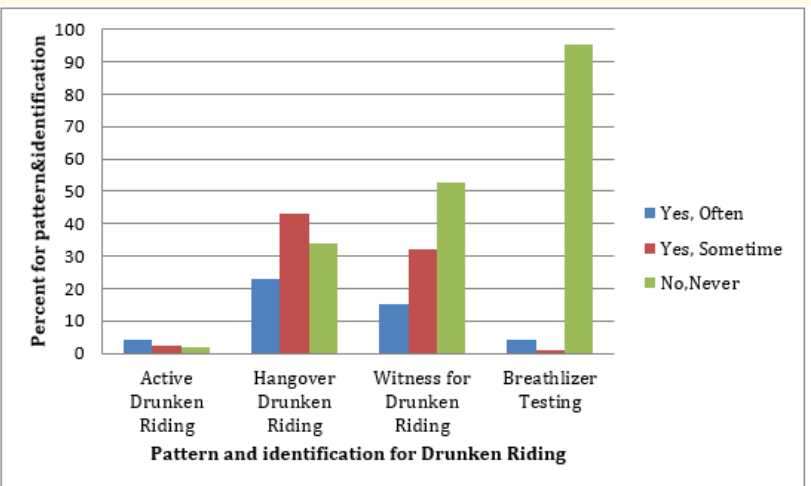

Figure 2: Drunken riding among commercial motorcyclists.

(41.7\%) disagreed and about 58 (23\%) agreed yes often riding with hangover on the morning of next day. In addition, 86 (34.1\%) said no, never do that but most of them said yes, sometime that accounts about 108 (42.9\%) 133 (52.4\%) of respondents said they did not see others riding while drunk. Only 38 (15.1\%) said no, they did not see others riding while drunk while 81 (32.1\%) said yes but sometime and $95.2 \%$ of respondents agreed did not tested by breathalyzer for detecting their alcohol intake status.

Associated factors for penalization among commercial motorcyclists in Dodoma city

The respondents asked if they penalized in the past twelve months against traffic violation and reason for it. The majority, 238 respondents (94.4\%) were penalized with different reasons in a year 2018 and only 14 (5.6\%) were not penalized in the same year following traffic violation. Reasons for penalization differs among respondents and distinguished by "yes" if the reason made the respondents penalized and "no" if the reason was not as shown in figure 3 . 
Compliances of Road Safety Practices and Associated Factors for Penalization against Traffic Offences among Commercial Motorcyclists: A Case of Dodoma City, Tanzania

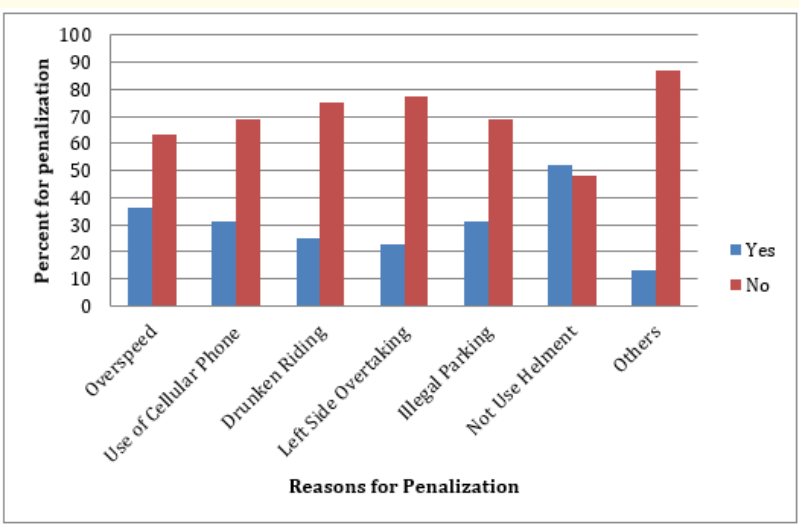

Figure 3: Reasons for penalization.

This indicates that $52 \%$ of the respondents agreed were penalized because of not using helmet when riding followed by overspeed, $36.4 \%$, use of cellular phones when riding $31.3 \%$, illegal parking, 31.3\%, drunken riding, 25\%, left side overtaking and others this includes, road insurance, improper of use of indicator, riding without riding license that accounts for $13.1 \%$.

Researcher was interested also to see if personal characteristics influence penalizations. To respond on it, bivariate and multivariate analysis conducted to identify the association and its strength. Prior running binary logistic regression, colliniality diagnostic was checked to detect the problem of multicolliniality the result was satisfied with the absence of multicolliniality for riding experience $(\mathrm{VIF}=1.14)$, possession of riding license $(\mathrm{VIF}=1.84)$ and awareness on speed limit (VIF = 1.78).

\begin{tabular}{|l|c|c|c|c|c|c|}
\hline & \multicolumn{5}{|c|}{ Penalization for Traffic Violation } \\
\hline Risk Factor on Penalization & $\begin{array}{c}\text { Yes } \\
\mathbf{n}=\mathbf{2 3 8}(\%)\end{array}$ & $\begin{array}{c}\text { No } \\
\mathbf{n}=\mathbf{1 4}(\%)\end{array}$ & $\begin{array}{c}\chi^{\mathbf{2}} \\
\text { P-Value }\end{array}$ & A0R & $\mathbf{9 5 \%}$ CI & P-Value \\
\hline Marital Status & & & & & \\
\hline In Relation & $87.0 \%$ & $97.3 \%$ & 10.15 & 0.69 & $0.1-2.5$ & 0.58 \\
\hline Not in Relation (Ref) & $13.0 \%$ & $2.7 \%$ & 0.01 & & & \\
\hline Riding Experience & & & & & & \\
\hline 1-3 Years & $96.3 \%$ & $83.8 \%$ & 9.39 & 4.0 & $1.8-8.7$ & $<0.001$ \\
\hline$\geq 4$ Years (Ref) & $3.7 \%$ & $16.2 \%$ & 0.02 & & & \\
\hline Possession of Active Riding License & & & & & & \\
\hline Yes & $88.1 \%$ & $98.7 \%$ & 12.85 & 0.14 & $0.03-0.68$ & 0.01 \\
\hline No (Ref) & $11.9 \%$ & $1.3 \%$ & P<0.001 & & & \\
\hline Attending BLS Training & & & & & & \\
\hline Yes & $84.2 \%$ & $95.3 \%$ & 4.10 & 0.78 & $0.15-3.9$ & 0.76 \\
\hline No (Ref) & $15.8 \%$ & $4.7 \%$ & 0.04 & & & \\
\hline Awareness on Speed Limit & & & & & & \\
\hline Aware & $88.7 \%$ & $98.8 \%$ & -18.03 & 0.16 & $0.02-1.02$ & 0.05 \\
\hline
\end{tabular}

Table 4: Multivariate analysis on associated factors for penalization.

Source: Field data, (2019).

Multivariate analysis with a PAC of $94.4 \%$ and Omni bust, $\chi^{2}(5)=$ 21.03; $\mathrm{p}<0.001$ showed that, there was a statistical significant relationship between riding experience (AOR 4.0; 95\% CI: 1.83, 8.72; $\mathrm{p}<0.001$ ), possession of active riding license (AOR 0.14; $95 \% \mathrm{CI}$ :
$0.03,0.68 ; \mathrm{p}<0.01$ ) with penalization among commercial motorcyclists. Nevertheless, in case of awareness on riding speed limit current study revealed that, significant association with penalization in marginal p-value $\left(\chi^{2}\right.$ value $=18.3$, AOR 0.16 ; 95\% CI: $0.02,1.02$; 
p 0.05) against penalization for traffic violation. However, marital status of participants $(\mathrm{p}=0.58)$ and attending basic life training prior to intervention $(\mathrm{p}=0.76)$ did not show significance strength association with penalization [15-20].

\section{Discussion}

More than third quarter of the participants were never tested by Breathalyzer test, this might be due to lack of the test or neglected as perceived by traffic polices. In the side of driving license; more than half didn't possess and therefore riding motorcycles without licensed, but the study revealed that. Participants who were possessing license and awareness on speed limit were less likely to be penalized and those with riding experience (1 - 3 yrs) were four times more likely to be penalized on traffic offences.

\section{Conclusion}

The current study shows that compliances of road safety practices among commercial motorcyclists was low as evidenced by most of commercial motorcyclists were penalized due to riding without wearing helmet, use of cellular phones when riding, drunken riding, left sided overtaking, and other reasons like riding without road insurance and license. This findings will guide the policy makers in future policy development and Tanzania Traffic Force in collaboration with National Road Safety Council to in continuing controlling and supervising the issues of road safety practices among commercial motorcyclists using Road Traffic Act CAP 168 of 1973 part I to $\mathrm{V}$ and more effort to be put in part VI (a) Enforcement by penalize all commercial motorcyclists with traffic offences. Participatory training on best road safety practices must also be done by traffic officers.

\section{Acknowledgements}

We acknowledge the following individuals for developing this paper: Makota and Mango Family for sponsorship and financial support. Again, we acknowledging the colleagues; Mr. Peter Soko for his tireless technical support throughout the manuscript preparation process.

\section{Conflict of Interest}

Authors did not have financial interest or any conflict of interest exists in this study.

\section{Bibliography}

1. Peltzer K. "Road use behavior in Sub-Saharan Africa". Public Health 122.12 (2011): 1399-1406.

2. Haulle E and Kisiri. "The impact of road accidents to the community of iringa municipality: Challenges in Reducing Risks". International and Multidisciplinary Journal of Social Sciences 5.3 (2016): 253-280.

3. Ministry of Home Affair. Crime and Traffic Incident report by (2016).

4. Chiduo W and Minja P. "Road safety in Tanzania: What are the problems? Technology Transfer in Road Transportation in Africa". Arusha International Conference Centre, Tanzania, 2325 May (2001).

5. Daily News (2018).

6. The Citizen. "Implementation of National Road safety operation and road safety week campaign" (2017).

7. World Life Expectancy (2017).

8. Boniface R., et al. "Factors affecting road traffic injuries in Tanzania”. Pan African Medical Journal 8688 (2016): 1-7.

9. Msava E. "The impact of motorcycle road accidents in Tanzania: A case study of Morogoro municipality" (2013).

10. Polit D and Beck C. "Nursing research: Generating and assessing evidence for nursing practice" (8th ed.). Philadelphia: Lippincott, Williams and Wilkins (2008).

11. Varkevisser M., et al. "Designing and conducting Health systems research projects: Proposal Development and Fieldwork" (2003): 1.

12. Dodoma Roads Network, Tanroads (2016).

13. Atubi A and O Onokala. "Contemporary Analysis of Variability in Road Traffic Accidents in Lagos State, Nigeria”. Journal of African Geographical Review 28 (2009): 11-41.

14. Krejcie R and Morgan D. "Determining sample size for research activities". Educational and Psychological Measurement 30 (1970): 607-610.

15. Mugenda 0. "Research Methods: A quantitative Approach". Nairobi: African Center of Technology Studies (1999). 
16. Chang H-L and Yeh T-H. "Motorcyclist accident involvement by age, gender, and risky behaviors in Taipei, Taiwan". Transportation Research Part F 10 (2006): 109-122.

17. Daily News. "Increasing number of "bodaboda" accidents worries parliament" (2017).

18. Hussain L and Redmond A. "Are pre-hospital deaths from accidental injury prevented?" BioMed Journal 308 (1994): 10771080.

19. Livingstone D. "Informal learning: Conceptual distinctions and preliminary findings”. Counter prints 249 (2006): 203-227.

20. Zimmerman K., et al. "Road traffic injury on rural roads in tanzania : measuring the effectiveness of a road safety program". Traffic Injury Prevention (2015): 1-5.

Volume 5 Issue 8 August 2021

(C) All rights are reserved by Evaristus Peter Makota. 